\title{
Clinicopathological characteristics and prognostic factors for primary thyroid lymphoma: report on 28 Chinese patients and results of a population- based study
}

This article was published in the following Dove Press journal:

Cancer Management and Research

\author{
Endong Chen,' Qiaolin \\ Wu, ${ }^{2}$ Yixiang Jin, ' Wenxu \\ Jin,' Yefeng Cai,' Qingxuan \\ Wang,' Xiaohua Zhang,' \\ Ouchen Wang,' Quan Li,' \\ Zhouci Zheng ${ }^{3}$ \\ 'Department of Thyroid and Breast \\ Surgery, The First Affiliated Hospital \\ of Wenzhou Medical University, \\ Wenzhou, Zhejiang, People's \\ Republic of China; ${ }^{2}$ Department \\ of Anesthesiology, The First \\ Affiliated Hospital of Wenzhou \\ Medical University, Wenzhou, \\ Zhejiang, People's Republic of \\ China; ${ }^{3}$ Department of Head and \\ Neck Surgery, The Second Affiliated \\ Hospital and Yuying Children's \\ Hospital of Wenzhou Medical \\ University, Wenzhou, Zhejiang, \\ People's Republic of China
}

Correspondence: Quan Li Department of Thyroid and Breast Surgery, The First Affiliated Hospital of Wenzhou Medical University, Nanbaixiang Street, Wenzhou, Zhejiang 325000, People's Republic of China Tel/fax: +8657755579462

Email lqoncology@126.com

Zhouci Zheng

Department of Head and Neck Surgery, The Second Affiliated Hospital and Yuying Children's Hospital of Wenzhou Medical University, 109 Xueyuanxi Street, Wenzhou, Zhejiang 325000, People's

Republic of China

Email 424505514@qq.com

\begin{abstract}
Objectives: Few studies on prognostic indicators for primary thyroid lymphoma (PTL) have been presented due to the uncommon nature of the tumor. This is the first study to explore the independent prognostic factors in the 2 PTL subtypes.

Methods: We retrospectively reviewed 1,653 cases of PTL. The cases comprised 28 Chinese patients from a local cohort and 1,625 patients from the Surveillance, Epidemiology, and End Results database from 1973 to 2013. Statistical analysis was performed to determine the demographics and prognostic factors of PTL patients.

Results: The disease-specific survival (DSS) and prognostic indicators were significantly different between patients with extranodal marginal zone B-cell lymphoma of the mucosa-associated lymphoid tissue (MALT) and patients with diffuse large B-cell lymphoma (DLBCL). Patients with MALT lymphoma were younger $(P=0.011)$ and had lower clinical stage $(P=0.014)$ compared to patients with DLBCL. Cox regression analysis revealed that age, treatment modalities employed, clinical stage, and number of other types of cancer were independent prognostic factors for DLBCL patients.

Conclusion: PTL demonstrates specific clinical features and is associated with a relatively good prognosis. Older age is associated with poor DSS in both MALT patients and DLBCL patients. Additionally, combination of different treatment modalities is associated with improved DSS in DLBCL patients.
\end{abstract}

Keywords: primary thyroid lymphoma, SEER database, disease-specific survival, combined modality treatment, prognosis

\section{Introduction}

Lymphoma is one of the most common types of malignancy in human beings, which often develops into extranodal lymphoma in certain organs and tissues, such as in the gastrointestinal tract and on the skin. ${ }^{1}$ Primary thyroid lymphoma (PTL) is a rare type of extranodal lymphoma, which is defined as lymphoma that involves only the thyroid or the thyroid and regional nodes without metastasis to other areas at the time of diagnosis. ${ }^{2}$ PTL, most of which are non-Hodgkin's lymphoma (NHL) of B-cell origin, accounts for approximately $1 \%-5 \%$ of thyroid malignancies and $2 \%$ of all extranodal lymphomas. PTL predominantly affects elderly female patients, who are older than 70 years. Lymphocytic thyroiditis may be involved in the development of PTL by allowing lymphoid cell infiltration of the thyroid bed. ${ }^{3}$ The common histological 
subtypes are extranodal marginal zone B-cell lymphoma of the mucosa-associated lymphoid tissue (MALT) and diffuse large B-cell lymphoma (DLBCL).

Constructing a database, which includes the information of patients with PTL, for the evaluation of possible prognostic factors and optimal treatment modalities is difficult due to the rarity of the condition. A few studies have discussed the potential pathologic predictors of survival for PTL. ${ }^{4,5}$ However, the prognostic factors between PTL subtypes, such MALT and DLBCL, have yet to be explored.

The present study aims to review and analyze the outcome of patients treated with PTL at the 2 affiliated hospitals of Wenzhou Medical University. The study also aims to discover potential associations among patient demographics, pathologic features, and clinical characteristics in different PTL subtypes using the Surveillance, Epidemiology, and End Results (SEER) database.

\section{Patients and methods}

\section{Patient characteristics}

From 2005 to 2017, 28 patients with PTL who underwent treatments at the 2 affiliated hospitals of Wenzhou Medical University were identified and evaluated. The mean age at diagnosis was 59 years, with $79 \%$ of the patients being female. Moreover, men were younger than women at the age of diagnosis ( 40 vs 64 years, respectively, $P=0.003$ ). Routine ultrasonography detected PTL as thyroid nodules in 26 out of 28 patients (92.8\%). Preoperative peripheral blood count and biochemical tests were almost within the normal range. All samples were reviewed retrospectively by 2 pathologists to confirm histological diagnosis. All patients had histologic verification of PTL, either from a needle biopsy $(n=2)$ or by surgery $(n=26)$. Immunohistochemical tests showed an abnormal increase in Ki-67 in most of the patients (Table 1 provides additional details and information). Furthermore, the Ann Arbor system was used to stage these patients. The

Table I Clinical information of local PTL patients

\begin{tabular}{|c|c|c|c|c|c|c|c|c|c|}
\hline Patient & Gender & Age (y) & Ki-67 & $\begin{array}{l}\text { Histological } \\
\text { type }\end{array}$ & $\begin{array}{l}\text { Clinical } \\
\text { stage }\end{array}$ & Treatment & Surgical type & $\begin{array}{l}\text { Number of } \\
\text { other cancers }\end{array}$ & $\begin{array}{l}\text { Disease-specific } \\
\text { survival (months) }\end{array}$ \\
\hline I & Female & 79 & $85 \%$ & DLBCL & II & $S+C$ & Lobectomy & 0 & 4 \\
\hline 2 & Female & 80 & NA & DLBCL & III & None & None & I & 0 \\
\hline 3 & Female & 85 & $80 \%$ & DLBCL & II & None & None & 0 & I \\
\hline 4 & Female & 71 & $70 \%$ & Other & ॥ & $S+C$ & Lobectomy & 0 & 24 \\
\hline 5 & Female & 65 & $70 \%$ & MALT & I & S & Lobectomy & 0 & 33 \\
\hline 6 & Male & 41 & $70 \%$ & DLBCL & II & $S+C$ & Partial lobectomy & 0 & 26 \\
\hline 7 & Female & 52 & $80 \%$ & MALT & I & $\mathrm{S}$ & Partial lobectomy & 0 & 39 \\
\hline 8 & Female & 50 & $30 \%$ & MALT & ॥ & $S+C$ & Lobectomy & 0 & 38 \\
\hline 9 & Female & 63 & $80 \%$ & Other & ॥ & $S+C$ & Thyroidectomy & 0 & 33 \\
\hline 10 & Female & 73 & $50 \%$ & MALT & $\|$ & $S+C$ & Thyroidectomy & 0 & 61 \\
\hline II & Male & 28 & $70 \%$ & DLBCL & II & $S$ & Thyroidectomy & 0 & 25 \\
\hline 12 & Female & 65 & NA & DLBCL & I & $S+C$ & Lobectomy & I & 70 \\
\hline 13 & Female & 39 & $50 \%$ & DLBCL & II & $S+C$ & Thyroidectomy & 0 & 7 \\
\hline 14 & Male & 73 & $10 \%$ & Other & 1 & S & Thyroidectomy & 0 & 77 \\
\hline 15 & Male & 57 & $70 \%$ & MALT & II & $\mathrm{S}$ & Thyroidectomy & 0 & 84 \\
\hline 16 & Female & 60 & $70 \%$ & MALT & I & $S+C$ & Lobectomy & 0 & 97 \\
\hline 17 & Female & 80 & $70 \%$ & DLBCL & ॥ & S & Lobectomy & 0 & 1 \\
\hline 18 & Female & 72 & $50 \%$ & MALT & 1 & $\mathrm{~s}$ & Lobectomy & 0 & 122 \\
\hline 19 & Male & 15 & $50 \%$ & Other & IV & $S+C$ & Lobectomy & 0 & 117 \\
\hline 20 & Female & 41 & $80 \%$ & DLBCL & I & $\mathrm{S}$ & Partial lobectomy & 0 & $13 \mid$ \\
\hline 21 & Female & 59 & $30 \%$ & MALT & 1 & $S+C$ & Thyroidectomy & 0 & 28 \\
\hline 22 & Female & 47 & $70 \%$ & Other & $\|$ & $\mathrm{S}$ & Thyroidectomy & 0 & 29 \\
\hline 23 & Female & 62 & $50 \%$ & MALT & $\|$ & S & Thyroidectomy & 0 & 26 \\
\hline 24 & Female & 80 & $70 \%$ & MALT & I & S & Thyroidectomy & 0 & 21 \\
\hline 25 & Female & 45 & $80 \%$ & MALT & I & S & Thyroidectomy & 0 & 23 \\
\hline 26 & Female & 77 & $80 \%$ & DLBCL & ॥ & $S+C$ & Partial lobectomy & 0 & 4 \\
\hline 27 & Male & 28 & $70 \%$ & MALT & 1 & $\mathrm{~S}$ & Lobectomy & 0 & 39 \\
\hline 28 & Female & 61 & $85 \%$ & MALT & I & S & Lobectomy & 0 & 33 \\
\hline
\end{tabular}

Abbreviations: $\mathrm{C}$, chemotherapy; DLBCL, diffuse large B-cell lymphoma; MALT, extranodal marginal zone B-cell lymphoma of mucosa-associated lymphoid tissue; NA, not available; PTL, primary thyroid lymphoma; S, surgery; $y$, years. 
patients whose samples were used had provided written informed consent for their use in future research.

Characteristics qualifying patients for surgical procedures are as follows:

1. Rapidly growing thyroid tumor with compression symptoms involving the trachea and adjacent structures.

2. The tumor cannot be diagnosed by preoperative examinations and biopsy.

3. Patient strongly demands surgical procedure.

Characteristics of qualifying patients for combined treatment are as follows:

1. Rapidly growing thyroid tumor with compressive symptoms involving the trachea and adjacent structures.

2. The tumor cannot be diagnosed by preoperative examinations and biopsy.

3. Aggressive PTL subtypes confirmed by postoperative immunohistochemical diagnosis.

4. Patients with advanced clinical stage.

5. Patient provides permission for combined treatment.

The SEER 18 database between 1973 and 2013 was utilized to analyze the frequency, treatment, and survival information for patients with PTL. The database comprises approximately $28 \%$ of the US population. The coding system of the International Classification of Diseases for Oncology, Third Edition (ICD-O-3), was used to select patients from the SEER database with primary tumors originating in the thyroid (ICD-O-3 code C73.9), and histology-specific codes (ICD-O-3 codes 9590-9758) were then used to identify those with PTL. A total of 1,625 patients with PTL were identified in the SEER 18 database from 1973 to 2013. Clinical and pathological variables (eg, age, gender, and marital status; tumor stage, differentiation, and number of other types of cancer; and treatment modalities employed) were analyzed. The SEER database does not contain any identifying patient information.

Ethical approval for this study was obtained from the ethical committee of the two affiliated hospitals of Wenzhou Medical University. Written informed consent was obtained from all of the local cohort participants.

\section{Treatments}

In the local cohort, almost all of the patients who came to our hospital sought medical assistance due to rapidly enlarging thyroid nodules with a varying extent of dyspnea. Most patients with PTL had been treated with surgery $(n=26$, $92.9 \%$ ); the other 2 patients had surgical contraindications and refused surgery. Twelve patients (42.9\%) had chemotherapy as individualized postoperative treatment, which consisted of rituximab, cyclophosphamide, doxorubicin, vincristine, and prednisone (RCHOP regimen). Generally, 4 to 8 cycles of chemotherapy were administered at 3-week intervals. Treatment-related toxicity was not documented in any patients. In the SEER cohort, 901 (55.4\%) patients with PTL underwent surgery treatment and $858(52.8 \%)$ patients underwent radiotherapy. Individualized treatment included surgery alone $(n=472,29.1 \%)$, radiotherapy alone $(n=429,26.4 \%)$, or combined surgery and radiotherapy $(n=429,26.4 \%)$.

\section{Statistical analysis}

The Kaplan-Meier method and log-rank tests were used to determine disease-specific survival (DSS). The Cox regression analysis was performed to evaluate the prognostic factors of patients with PTL. SPSS software (version 18.0, SPSS Inc., Chicago, IL, USA) was used for all statistical analysis. All $P$-values were 2 sided, and a $P$-value of $<0.05$ was considered statistically significant.

\section{Results}

\section{Follow-up data of local cohort}

The sample of 28 patients included 6 men (21.4\%) and 22 women $(78.6 \%)$, with a male-to-female ratio of 0.27 . Age range was 15-85 (mean, 59 years), and the median DSS was 31 months (range, $0-131$ months). In 26 out of the 28 patients (92.8\%), PTL was detected as thyroid nodules during a routine examination. Conversely, only 2 of the patients $(7.2 \%)$ presented lymphoma-associated symptom, such as night sweat (Table 1). PTL patients who underwent surgery alone (median DSS, 52.2 months) or combined treatment (median DSS, 42.4 months) showed a longer DSS compared with patients who underwent no treatment (median DSS, 0.5 months). However, the finding was not statistically significant $(P>0.05)$. The DSS between the 2 treatment groups was not statistically different $(P>0.05)$.Most of the patients were in early stages of PTL (26/28). Patients with MALT and DLBCL accounted for the majority of all patients (82.1\%). Between these 2 subtypes of PTL, patients with MALT showed a tendency of younger age at presentation $(P=0.011)$, lower clinical stage $(P=0.014)$, and longer median DSS compared with patients with DLBCL (Table 2). An independent prognostic factor was not found due to limited case counts.

\section{Relationship between PTL subtypes and clinicopathological features}

The relationship between MALT and DLBCL groups from the SEER cohort was investigated (Table 3 ). The results revealed that younger age $(P<0.001)$ and lower clinical stage 
Table 2 The relationship between different subtypes of PTL and clinicopathologic features in the local cohort

\begin{tabular}{|c|c|c|c|}
\hline $\begin{array}{l}\text { Clinicopathologic } \\
\text { features }\end{array}$ & $\operatorname{MALT}(n=13)$ & $\begin{array}{l}\text { DLBCL } \\
(n=10)\end{array}$ & $P$-value \\
\hline \multicolumn{4}{|l|}{ Age (years) } \\
\hline Mean \pm SD & $58.77 \pm 13.37$ & $61.50 \pm 21.77$ & 0.011 \\
\hline$\leq 55$ & $4(31)$ & $4(40)$ & 0.685 \\
\hline$>55$ & $9(69)$ & $6(60)$ & \\
\hline \multicolumn{4}{|l|}{ Survival months } \\
\hline Mean \pm SD & $49.54 \pm 31.96$ & $26.90 \pm 42.43$ & 0.018 \\
\hline Median & 38 & 5.5 & \\
\hline Gender & & & I \\
\hline Male & $2(15)$ & $2(20)$ & \\
\hline Female & II (85) & $8(80)$ & \\
\hline Marital status & & & 0.127 \\
\hline Married & $12(92)$ & $6(60)$ & \\
\hline Unmarried & $I(8)$ & $4(40)$ & \\
\hline Clinical stage & & & 0.014 \\
\hline 1 & $9(69)$ & $I(10)$ & \\
\hline II & $4(3 I)$ & $8(80)$ & \\
\hline III & $0(0)$ & $\mathrm{I}(10)$ & \\
\hline S & & & 0.178 \\
\hline Yes & $13(100)$ & $8(80)$ & \\
\hline No & $0(0)$ & $2(20)$ & \\
\hline$S+C$ & & & 0.417 \\
\hline Yes & $4(3 I)$ & $5(50)$ & \\
\hline No & $9(69)$ & $5(50)$ & \\
\hline Type of operation & & & 0.24 \\
\hline Partial lobectomy & I (8) & $3(30)$ & \\
\hline Lobectomy & $7(54)$ & $3(30)$ & \\
\hline Thyroidectomy & $5(38)$ & $2(20)$ & \\
\hline Number of other cancers & & & 0.178 \\
\hline None & $13(100)$ & $8(80)$ & \\
\hline 1 & $0(0)$ & $2(20)$ & \\
\hline
\end{tabular}

Note: Data is presented as $\mathrm{n}(\%)$ unless otherwise stated.

Abbreviations: C, chemotherapy; DLBCL, diffuse large B-cell lymphoma; MALT, extranodal marginal zone B-cell lymphoma of the mucosa-associated lymphoid tissue; PTL, primary thyroid lymphoma; S, surgery.

$(P<0.001)$ were significantly related to the MALT subtype. Moreover, surgeons were more likely to select surgery alone $(P<0.001)$ or its combination with radiation $(P<0.001)$ for patients with MALT. Specifically, more aggressive surgical treatments were performed on MALT patients $(P<0.001)$. With regard to medical history, patients with MALT more often suffered from other types of cancer $(P<0.001)$. Moreover, race $(P<0.001)$ and geographic region $(P<0.001)$ were markedly different among the 2 groups. No significant associations were observed between the 2 PTL subtypes and gender, marital status, and mean survival months $(P>0.05)$.

\section{Relationship between DSS rate and clinicopathological features among different PTL subtypes}

Further exploration was performed to study the association between DSS rate and clinicopathological features among
Table 3 The relationship between different subtypes of PTL and clinicopathologic features in the SEER cohort

\begin{tabular}{|c|c|c|c|}
\hline $\begin{array}{l}\text { Clinicopathologic } \\
\text { features }\end{array}$ & $\begin{array}{l}\text { MALT } \\
(n=258)\end{array}$ & $\begin{array}{l}\text { DLBCL } \\
(n=850)\end{array}$ & $P$-value \\
\hline \multicolumn{4}{|l|}{ Age (years) } \\
\hline Mean \pm SD & $62.36 \pm 13.45$ & $67.05 \pm 13.44$ & $<0.001$ \\
\hline$\leq 55$ & $177(68.6)$ & $684(80.5)$ & $<0.001$ \\
\hline$>55$ & $8 I(3 I .4)$ & $166(19.5)$ & \\
\hline \multicolumn{4}{|l|}{ Survival months } \\
\hline Mean \pm SD & $75.22 \pm 52.96$ & $92.88 \pm 87.27$ & 0.334 \\
\hline Median & 69 & 77 & \\
\hline Gender & & & 0.069 \\
\hline Male & $79(30.6)$ & $212(24.9)$ & \\
\hline Female & $179(69.4)$ & $638(75.1)$ & \\
\hline Marital status & & & 0.119 \\
\hline Married & $150(58.1)$ & $456(53.6)$ & \\
\hline Unmarried & $95(36.8)$ & $364(42.8)$ & \\
\hline Clinical stage & & & 0.014 \\
\hline I & $190(73.6)$ & $419(49.3)$ & \\
\hline II & $50(19.4)$ & $238(28.0)$ & \\
\hline III & $3(0.01)$ & $17(2.0)$ & \\
\hline IV & $8(0.03)$ & $74(8.7)$ & \\
\hline S & & & $<0.001$ \\
\hline Yes & 235 (9I.I) & $465(54.7)$ & \\
\hline No & $23(8.9)$ & $385(45.3)$ & \\
\hline $\mathrm{R}$ & & & $<0.001$ \\
\hline Yes & $14(5.4)$ & $232(27.3)$ & \\
\hline No & $244(94.6)$ & $618(72.7)$ & \\
\hline$S+R$ & & & $<0.001$ \\
\hline Yes & $102(39.5)$ & $231(27.2)$ & \\
\hline No & $156(60.5)$ & $619(72.8)$ & \\
\hline Type of operation & & & $<0.001$ \\
\hline Partial lobectomy & $14(6.0)$ & $93(20.5)$ & \\
\hline Lobectomy & 99 (42.7) & $179(39.4)$ & \\
\hline Thyroidectomy & $119(41.3)$ & $182(40.1)$ & \\
\hline Number of other cancers & & & $<0.001$ \\
\hline None & $171(66.3)$ & $600(70.6)$ & \\
\hline 1 & $82(31.8)$ & $230(27.1)$ & \\
\hline 2 & $5(1.9)$ & $20(2.4)$ & \\
\hline Race & & & $<0.001$ \\
\hline White & $219(84.9)$ & $793(93.3)$ & \\
\hline Black & $8(3.1)$ & $14(1.7)$ & \\
\hline Others & $31(12.0)$ & $43(5.6)$ & \\
\hline Region & & & 0.012 \\
\hline Pacific coast & I2I (46.9) & 317 (37.3) & \\
\hline East & $74(28.7)$ & $24 I(28.4)$ & \\
\hline Northern & $46(17.8)$ & $204(24.0)$ & \\
\hline Southwest & $17(6.6)$ & $88(10.4)$ & \\
\hline
\end{tabular}

Note: Data is presented as $\mathrm{n}(\%)$ unless otherwise stated.

Abbreviations: DLBCL, diffuse large B-cell lymphoma; MALT, extranodal marginal zone B-cell lymphoma of the mucosa-associated lymphoid tissue; PTL, primary thyroid lymphoma; R, radiotherapy; S, surgery; SEER, Surveillance, Epidemiology, and End Results.

MALT and DLBCL groups. Patients with MALT have better DSS compared with patients with DLBCL (Figure 1A). In the MALT group, only older age $(P=0.006$; Figure $1 \mathrm{~B})$ could significantly shorten the DSS of patients. Geographic region, marital status, clinical stage, number of other types 
A

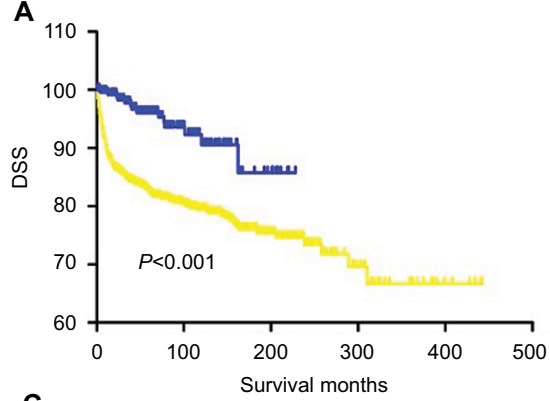

C

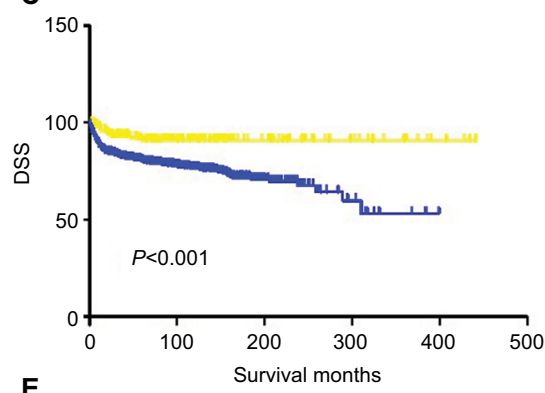

E

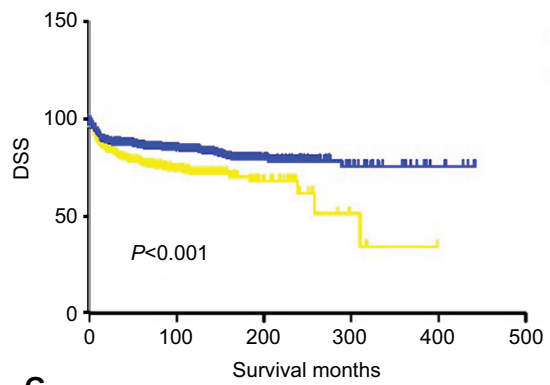

G

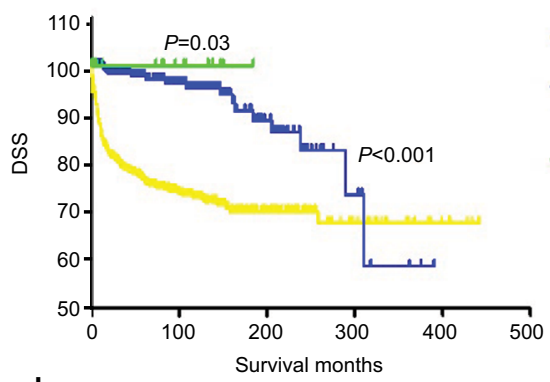

I

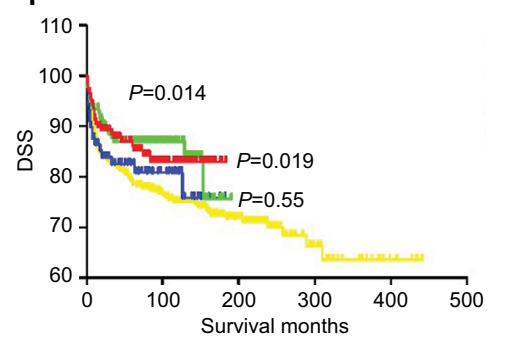

- DLBCL

$\perp$ MALT

$+\leq 55$ years

․ $>55$ years

500

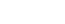

- Unmarried

+ Married

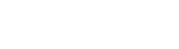

B
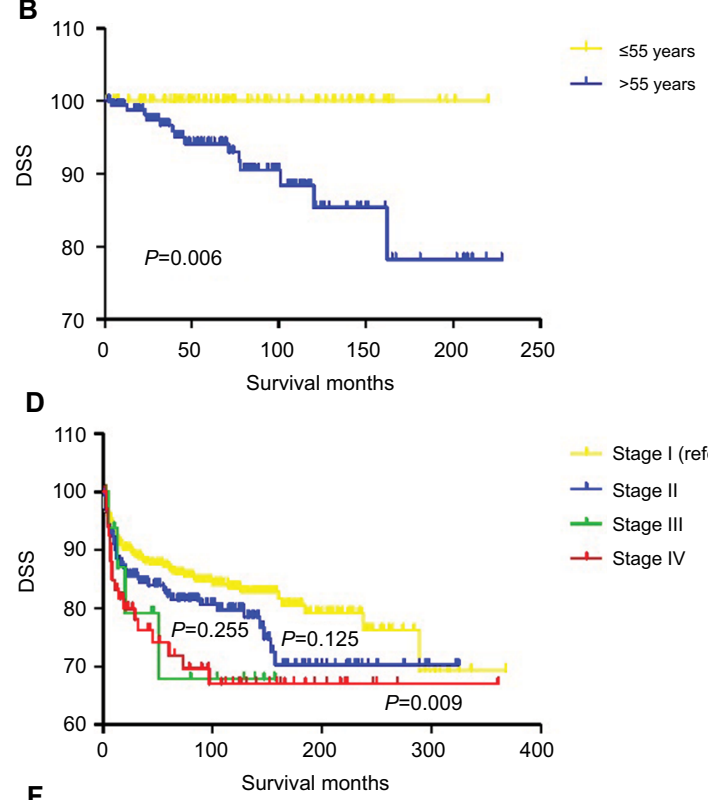

+ Stage I (reference)

+ Stage II

+ Stage III

+ Stage IV

$\mathbf{F}$

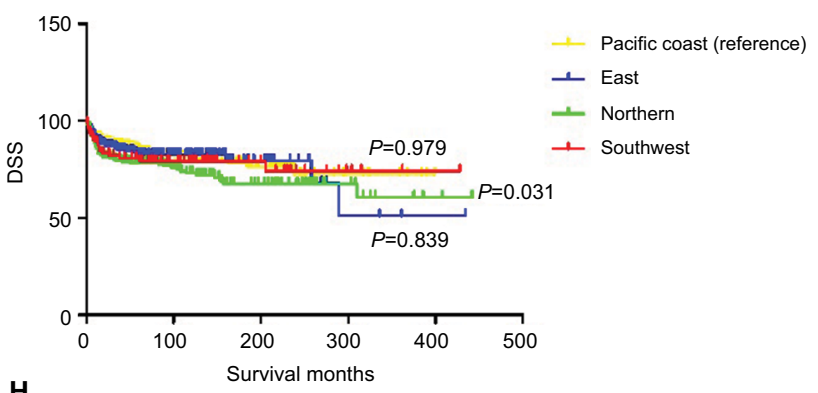

H

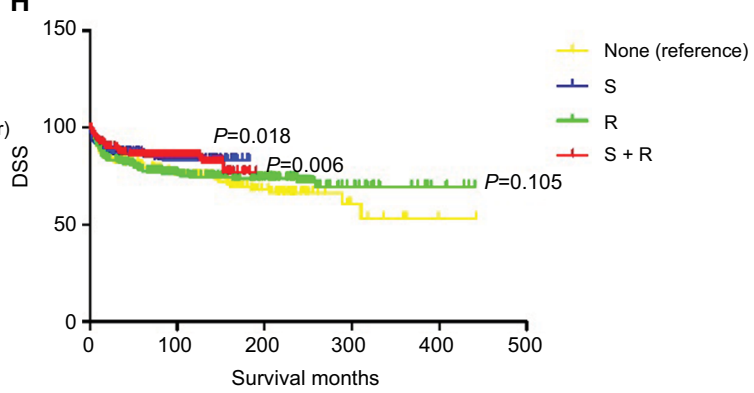

Figure I Relationship between DSS rate and clinicopathological features among different PTL subtypes.

Note: (A) Patients with MALT have better DSS compared with patients with DLBCL. (B) Older age ( $P=0.006)$ could significantly shorten the DSS of patients with MALT. (C-G) Lower DSS rate was associated with older age $(P<0.00 \mathrm{I})$, clinical stage of IV $(P=0.009)$, unmarried status $(P<0.00 \mathrm{I})$, residence in a northern region $(P=0.03 \mathrm{I})$, and presence of a single lymphoma $(P<0.05)$ in patients with DLBCL. $(H)$ Surgery alone $(P=0.018)$ or combined surgery and radiotherapy $(P=0.006)$ could markedly improve the DSS rate of DLBCL patients. (I) Aggressive surgical treatments, including thyroid lobectomy $(P=0.014)$ and near-total/total thyroidectomy $(P=0.019)$, could significantly prolong the DSS of DLBCL patients.

Abbreviations: DLBCL, diffuse large B-cell lymphoma; DSS, disease-specific survival; MALT, extranodal marginal zone B-cell lymphoma of the mucosa-associated lymphoid tissue; PTL, primary thyroid lymphoma. 
of cancer, and treatment modalities employed had no effect on the DSS of patients with MALT $(P>0.05)$. However, in the DLBCL group, lower DSS rate was associated with older age $(P<0.001$; Figure $1 C)$, clinical stage of IV $(P=0.009$; Figure 1D), unmarried status $(P<0.001$; Figure 1E), residence in the northern region $(P=0.031$; Figure $1 \mathrm{~F})$, and presence of a single lymphoma $(P<0.05$; Figure $1 \mathrm{G})$. In comparison with patients who accepted no treatment, surgery alone $(P=0.018)$ or combined surgery and radiotherapy $(P=0.006)$ could markedly improve the DSS rate of patients with DLBCL in terms of the treatment modalities employed (Figure 1H). Specifically, aggressive surgical treatments, including thyroid lobectomy $(P=0.014)$ and near-total/total thyroidectomy $(P=0.019)$, could significantly prolong the DSS of patients with DLBCL (Figure 1I). Gender and race did not affect the DSS of patients with PTL in either groups $(P>0.05)$.

\section{Prognostic factors analysis for different PTL subtypes}

The Cox regression analysis was also conducted to assess the prognostic factors of patients with MALT and DLBCL according to the follow-up data from the SEER database. Neither univariate nor multivariate Cox regression analysis could determine the proper prognostic factors from the aforementioned clinical features because of the relatively low mortality rate $(14 / 258,5.4 \%)$ of patients with MALT. In the DLBCL group, the univariate Cox regression analysis (Table 4) determined that older age (hazard ratio $[\mathrm{HR}]=3.5$, $95 \%$ confidence interval $[\mathrm{CI}]=2.019-6.069, P<0.001)$, clinical stage of IV $(\mathrm{HR}=1.918,95 \% \mathrm{CI}=1.163-3.161, P=0.011)$, unmarried status $(\mathrm{HR}=1.751,95 \% \mathrm{CI}=1.288-2.380$, $P<0.001)$, and residence in northern region $(\mathrm{HR}=1.494,95 \%$ $\mathrm{CI}=1.031-2.165, P=0.034)$ were significantly associated with poor prognosis for patients with DLBCL. Surgery alone ( $\mathrm{HR}=0.547,95 \% \mathrm{CI}=0.348-0.859, P=0.009)$ or combined surgery and radiotherapy $(\mathrm{HR}=0.491,95 \% \mathrm{CI}=0.314-0.769$, $P=0.002$ ) was also found to improve the DSS of DLBCL patients effectively. Aggressive surgical treatments, including thyroid lobectomy $(\mathrm{HR}=0.57,95 \% \mathrm{CI}=0.361-0.900$, $P=0.016)$ and near-total $/$ total thyroidectomy $(\mathrm{HR}=0.597$, $95 \% \mathrm{CI}=0.384-0.929, P=0.022$ ), were associated with better prognosis for these patients. Patients with DLBCL with another type of cancer $(\mathrm{HR}=0.237,95 \% \mathrm{CI}=0.142-0.397$, $P<0.001)$ could be a protective factor of DSS. Further multivariate Cox regression analysis revealed that age $(\mathrm{HR}=3.750,95 \% \mathrm{CI}=2.057-6.838, P<0.001)$, treatment modalities employed $(\mathrm{HR}=0.821,95 \% \mathrm{CI}=0.702-0.961$, $P=0.014)$, clinical stage $(\mathrm{HR}=1.203,95 \% \mathrm{CI}=1.021-1.418$,
Table 4 Univariate Cox regression analysis for DLBCL patients in the SEER cohort

\begin{tabular}{|c|c|c|c|}
\hline $\begin{array}{l}\text { Clinicopathologic } \\
\text { features }\end{array}$ & HR & $95 \% \mathrm{Cl}$ & $P$-value \\
\hline \multicolumn{4}{|l|}{ Age (years) } \\
\hline$\leq 55$ & I & & \\
\hline$>55$ & 3.5 & $2.0-6.1$ & $<0.001$ \\
\hline \multicolumn{4}{|l|}{ Gender } \\
\hline Male & I & & \\
\hline Female & 1.2 & $0.8-1.7$ & 0.317 \\
\hline \multicolumn{4}{|l|}{ Marital status } \\
\hline Married & 1 & & \\
\hline Unmarried & 1.8 & I.3-2.4 & $<0.001$ \\
\hline \multicolumn{4}{|l|}{ Clinical stage } \\
\hline I & I & & \\
\hline ॥ & 1.3 & $0.9-1.9$ & 0.129 \\
\hline III & 1.7 & $0.6-4.8$ & 0.287 \\
\hline IV & 1.9 & $1.2-3.2$ & 0.011 \\
\hline \multicolumn{4}{|l|}{ Treatments } \\
\hline None & 1 & & \\
\hline $\mathrm{S}$ & 0.5 & $0.3-0.9$ & 0.009 \\
\hline $\mathrm{R}$ & 0.8 & $0.5-1.1$ & 0.105 \\
\hline$S+R$ & 0.5 & $0.3-0.8$ & 0.002 \\
\hline \multicolumn{4}{|l|}{ Type of operation } \\
\hline None & 1 & & \\
\hline Partial lobectomy & 0.9 & $0.5-1.4$ & 0.57 \\
\hline Lobectomy & 0.6 & $0.4-0.9$ & 0.016 \\
\hline Thyroidectomy & 0.6 & $0.4-0.9$ & 0.022 \\
\hline \multicolumn{4}{|c|}{ Number of other cancers } \\
\hline None & $\mathrm{I}$ & & \\
\hline $\mathrm{I}$ & 0.2 & $0.1-0.4$ & $<0.001$ \\
\hline 2 & 0 & 0 & 0.935 \\
\hline \multicolumn{4}{|l|}{ Race } \\
\hline White & $\mathrm{I}$ & & \\
\hline Black & 1.1 & $0.3-3.4$ & 0.89 \\
\hline Others & 1.0 & $0.5-2.0$ & 0.97 \\
\hline \multicolumn{4}{|l|}{ Region } \\
\hline Pacific coast & I & & \\
\hline East & 0.9 & $0.7-1.5$ & 0.947 \\
\hline Northern & 1.5 & $1.0-2.2$ & 0.034 \\
\hline Southwest & 1.06 & $0.6-1.8$ & 0.833 \\
\hline
\end{tabular}

Abbreviations: $\mathrm{Cl}$, confidence interval; $\mathrm{DLBCL}$, diffuse large $\mathrm{B}$-cell lymphoma; $\mathrm{HR}$, hazard ratio; R, radiotherapy; S, surgery; SEER, Surveillance, Epidemiology, and End Results.

$P=0.027)$, and number of other types of cancer $(\mathrm{HR}=0.205$, $95 \% \mathrm{CI}=0.116-0.360, P<0.001)$ were independent prognostic factors (Table 5).

\section{Discussion}

PTL is a rare condition, with an estimated incidence of less than $5 \%$ of thyroid malignancies and approximately $2 \%$ extranodal lymphomas. ${ }^{2}$ Histologically, the majority of PTL is NHL, which originated from B-cell lineage. ${ }^{6}$ Most patients with PTL had DLBCL, whereas approximately 
Table 5 Multivariate Cox regression analysis for DLBCL patients in the SEER cohort

\begin{tabular}{llll}
\hline Clinicopathologic features & HR & $\mathbf{9 5 \% ~ C l ~}$ & P-value \\
\hline Age & 3.8 & $2.1-6.8$ & $<0.00 \mathrm{I}$ \\
Treatments & 0.8 & $0.7-0.9$ & 0.014 \\
Clinical stage & 1.2 & $1.0-1.4$ & 0.027 \\
Marital status & 0.7 & $0.5-1.0$ & 0.086 \\
Number of other cancers & 0.2 & $0.1-0.4$ & $<0.00 \mathrm{I}$ \\
\hline
\end{tabular}

Abbreviations: $\mathrm{Cl}$, confidence interval; $\mathrm{DLBCL}$, diffuse large $\mathrm{B}$-cell lymphoma; $\mathrm{HR}$ hazard ratio; SEER, Surveillance, Epidemiology, and End Results.

one-third of patients were found to have MALT. ${ }^{7}$ Prognosis varied with different PTL subtypes. Patients with MALT show better prognosis due to its more indolent behavior and more favorable response to therapy compared with DLBCL patients. However, the prognostic values of clinical features and treatment modalities employed in the 2 subtypes remain unknown. To the best of the authors' knowledge, this study is the first to explore the independent prognostic factors between the 2 different PTL subtypes.

In this study, we performed a retrospective analysis involving 28 patients and used statistical tools to analyze clinical data. Collectively, the results demonstrated that patients with PTL may benefit from both surgical procedures and combined treatments. Meanwhile, patients with MALT tended to be younger, have lower clinical stage, and have longer median DSS compared with DLBCL patients.

To avoid the discrepancies in the related prevalence of histologic subtypes, DSS, and independent prognostic factors caused by the limited case counts, ${ }^{5,8}$ the clinical features of the local cohort were initially compared with the SEER cohort, and no significant difference was found between the 2 cohorts (data not shown). Prior studies have found that approximately $90 \%$ of patients have early-stage PTL, ${ }^{9-11}$ which is similar to the present study $(92.8 \%, 26 / 28)$. DLBCL is universally considered as the most common subtype of PTL., ${ }^{2,12,13}$ However, in our study, DLBCL only accounted for $35.7 \%$ (10/28) of all PTL, which is considerably different from the rate reported previously. MALT, the major subtype of the present study, accounted for $46.4 \%$ (13/28) of all patients, which is higher than previously reported rates of $20 \%-40 \%{ }^{9,14}$ Further analysis of the local cohort revealed that significant differences were found in diagnostic age, clinical stage, and median DSS between the MALT and DLBCL groups, which was further confirmed by the SEER cohort analysis.

Although various treatments, such as surgery, chemotherapy, and radiotherapy, have been applied alone or in combination to cure PTL, no clear guidelines for therapy have emerged. Surgery that constitutes the foundation of treating rapidly growing thyroid tumors, including adenomas, at present plays only a marginal role limited to immediate interventions associated with compression symptoms involving the trachea and adjacent structures and is a significant element of palliative surgical management that ensures the patency of the respiratory tract prior to initiation of irradiation therapy. At present, the role of surgical treatment in PTL remains controversial. Some studies contended that surgery favorably influenced the outcome in patients with PTL in certain small case series. ${ }^{9,15}$ Derringer et $\mathrm{al}^{9}$ reported that 16 patients with MALT, who were only treated with surgery, reached a $100 \%$ overall survival (OS) rate after a 7-year follow-up. However, a study conducted by Mayo Clinic ${ }^{16}$ revealed that the combination of total thyroidectomy with adjuvant radiotherapy could not improve the long-term outcome compared with biopsy associated with radiotherapy in early stages. In the present study, almost all patients (26/28) initially underwent surgical treatment due to the dyspnea caused by the rapidly enlarging neck mass. The MALT group showed higher surgical rate (13/13) than the DLBCL group $(8 / 10)$, and more aggressive surgical treatments were performed on patients with MALT. Patients with MALT treated with surgery alone or in combination with chemotherapy also achieved a $100 \%$ DSS in this study (13/13). Moreover, $37.5 \%(3 / 8)$ of patients with DLBCL suffered from PTL recurrence within 3 years after their treatments. Analysis of the SEER cohort also validated that higher surgical rate and more complex treatment regimens were correlated with patients with MALT. In the SEER cohort, surgical treatment alone or in combination with radiotherapy could effectively improve the DSS of patients with DLBCL. In patients with MALT, surgical treatment alone cannot affect either OS or DSS of patients with MALT. However, surgical treatment, when combined with radiotherapy, significantly improved the OS of MALT patients.

Over the last several years, chemotherapy alone or in combination with radiation has become the primary treatment for PLT. ${ }^{17-19}$ Combined chemotherapy regimen, especially the RCHOP scheme, was the most common choice for NHL treatment. ${ }^{20,21}$ Most of the PTL subtypes were recommended to be treated by the combination of chemotherapy and radiotherapy even at early stages. ${ }^{22}$ Watanabe et $\mathrm{al}^{23}$ revealed that long-term outcomes of localized thyroid MALT lymphoma are favorable with combined treatment modalities. Cha et $\mathrm{al}^{24}$ found that radiotherapy alone for MALT and chemotherapy followed by radiotherapy for high-grade lymhoma can be effective treatment options for PTL. Mian et $\mathrm{al}^{25}$ reported 
that patients with DLBCL who underwent chemotherapy followed by radiotherapy had a statistically significantly longer progression-free survival time than those who received a single therapy. A literature review that included 211 patients conducted by Doria et $\mathrm{al}^{26}$ suggested that chemotherapy combined with radiation therapy could lower distant and overall recurrence rates compared with radiotherapy alone (overall recurrence $8 \%$ vs 37\%; distant recurrence 5\% vs $31 \%$ ). Moreover, Fuller et $\mathrm{al}^{27}$ reported that higher doses of radiotherapy combined with chemotherapy could lead to achievement of better local control for patients with DLBCL. The use of radiotherapy alone to cure PTL was uncommon, and only a few cases have reported that the sole use of radiotherapy could lead to a favorable prognosis for patients with MALT. ${ }^{15,28}$ Although insignificant, the present study revealed that patients in the local cohort who received surgical treatment combined with chemotherapy (RCHOP regimen) had a lower recurrence rate ( $8 \%$ vs $21 \%$ ) compared with surgical treatment alone. With a large number of patients, a different significant conclusion may have been reached. These findings suggested that local therapy of PTL alone was insufficient to cure diseases and combined systemic treatments may be warranted.

PTL prognosis heavily depends on the clinical stage. ${ }^{29}$ Previous studies have found that OS from PTL ranges from $56 \%$ to $90 \%{ }^{5,14}$ The patients with stage-I PTL have the best prognosis. The 5-year DSS for stage-I has been reported to be as high as $100 \%$ in certain case series. ${ }^{9,30}$ However, the 5-year DSS can dramatically decrease from $90 \%$ to $35 \%$ when the intrathyroidal disease becomes an extrathyroidal disease. In the current study, none of patients with stage-I PTL died during the follow-up, which was consistent with previous reports. In the SEER cohort, the 5-year OS and DSS for patients with stage-I PTL were $76.5 \%$ and $87.2 \%$, respectively, which was also within the range reported previously. The prognosis of PTL also varied from different histological classifications. ${ }^{29}$ Indolent subtypes, such as MALT, were commonly acknowledged to have a better prognosis than aggressive subtypes due to their relatively mild/benign behaviors and more positive response to therapy. The analysis of the SEER database also confirmed this finding. According to the follow-up data, the 5-year OS and DSS for patients with MALT reached 84.4\% and $96.1 \%$, respectively. Meanwhile, the 5-year OS and DSS for patients with DLBCL were $66.4 \%$ and $81.3 \%$, respectively, which was significantly lower than that of patients with MALT. Further analysis suggested that older age $(>55$ years) was negatively correlated with prognosis for patients with MALT and DLBCL. In addition, lower clinical stage, and multiple tumors predicted a good prognosis for patients with DLBCL.

The present study still has certain limitations. First, the SEER database did not include the information of chemotherapy in patients with PTL; thus, the role that chemotherapy alone or in combination with other treatments played in MALT or DLBCL treatment remains unknown. Second, we failed to take into account the presence of comorbidities (other than another cancer), the presence of extranodal disease, the performance status, or the size of PTL as prognostic factors, because information regarding these factors are not available in the SEER database. Third, determining the proper pathologic predictors for survival in People's Republic of China, especially in Eastern China, is difficult due to the small case size.

\section{Conclusion}

In conclusion, given the rarity of PTL, conducting prospective randomized trials to assess the prognostic factors is difficult. The current study presents a case series with 28 patients with PTL. Statistical analysis reveals that the age at diagnosis and the median DSS were significantly diverse among different PTL subtypes. The analysis of the SEER database indicated that older age could shorten the DSS of patients with MALT and DLBCL. Lower clinical stage and multiple tumors predicted good prognosis for patients with DLBCL. The multivariate analysis of SEER data identified the following independent prognostic factors for patients with DLBCL: age, treatment modalities employed, clinical stage, and number of other types of cancer. Patients with DLBCL could benefit from surgery alone or in combination with radiotherapy. No available prognostic factor was found in patients with MALT.

\section{Acknowledgments}

This work was supported by a grant from the National High Technology Research and Development Program of 863 Project of China (number 2012AA02A210), the Major Science and Technology Projects of Zhejiang Province (number 2015C03052), the Wenzhou Science and Technology Bureau (numbers Y20160126 and Y20170735), and the Scientific Research Incubator Project of The First Affiliated Hospital of Wenzhou Medical University (number FHY2014018).

\section{Disclosure}

The authors report no conflicts of interest in this work. 


\section{References}

1. Siegel RL, Miller KD, Jemal A. Cancer statistics, 2015. CA Cancer J Clin. 2015;65(1):5-29.

2. Ansell SM, Grant CS, Habermann TM. Primary thyroid lymphoma. Semin Oncol. 1999;26(3):316-323.

3. Tavares Bello C, Cassis J, Simoes H, Sequeira Duarte J. Nodular lymphocyte predominant Hodgkin lymphoma of the thyroid. Case Rep Endocrinol. 2016;2016:8756723.

4. Graff-Baker A, Roman SA, Thomas DC, Udelsman R, Sosa JA. Prognosis of primary thyroid lymphoma: demographic, clinical, and pathologic predictors of survival in 1,408 cases. Surgery. 2009;146(6):1105-1115.

5. DiBiase SJ, Grigsby PW, Guo C, Lin HS, Wasserman TH. Outcome analysis for stage IE and IIE thyroid lymphoma. Am J Clin Oncol. 2004;27(2):178-184.

6. Widder S, Pasieka JL. Primary thyroid lymphomas. Curr Treat Options Oncol. 2004;5(4):307-313.

7. Peixoto R, Correia Pinto J, Soares V, Koch P, Taveira Gomes A. Primary thyroid lymphoma: a case report and review of the literature. Ann Med Surg. 2017;13:29-33.

8. Quesada AE, Liu H, Miranda RN, et al. Burkitt lymphoma presenting as a mass in the thyroid gland: a clinicopathologic study of 7 cases and review of the literature. Hum Pathol. 2016;56:101-108.

9. Derringer GA, Thompson LD, Frommelt RA, Bijwaard KE, Heffess CS, Abbondanzo SL. Malignant lymphoma of the thyroid gland: a clinicopathologic study of 108 cases. Am J Surg Pathol. 2000;24(5): 623-639.

10. Meyer-Rochow GY, Sywak MS, Reeve TS, Delbridge LW, Sidhu SB. Surgical trends in the management of thyroid lymphoma. Eur J Surg Oncol. 2008;34(5):576-580.

11. Ruggiero FP, Frauenhoffer E, Stack BC Jr. Thyroid lymphoma: a single institution's experience. Otolaryngol Head Neck Surg. 2005;133(6):888-896.

12. Green LD, Mack L, Pasieka JL. Anaplastic thyroid cancer and primary thyroid lymphoma: a review of these rare thyroid malignancies. J Surg Oncol. 2006;94(8):725-736

13. Mack LA, Pasieka JL. An evidence-based approach to the treatment of thyroid lymphoma. World J Surg. 2007;31(5):978-986.

14. Niitsu N, Okamoto M, Nakamura N, Nakamine H, Bessho M, Hirano M. Clinicopathologic correlations of stage IE/IIE primary thyroid diffuse large B-cell lymphoma. Ann Oncol. 2007;18(7):1203-1208.

15. Tsang RW, Gospodarowicz MK, Pintilie M, et al. Localized mucosaassociated lymphoid tissue lymphoma treated with radiation therapy has excellent clinical outcome. J Clin Oncol. 2003;21(22):4157-4164.

16. Pyke CM, Grant CS, Habermann TM, et al. Non-Hodgkin's lymphoma of the thyroid: is more than biopsy necessary? World J Surg. 1992;16(4):604-609; discussion 609-610.
17. Ha CS, Shadle KM, Medeiros LJ, et al. Localized non-Hodgkin lymphoma involving the thyroid gland. Cancer. 2001;91(4):629-635.

18. Katna R, Shet T, Sengar M, et al. Clinicopathologic study and outcome analysis of thyroid lymphomas: experience from a tertiary cancer center. Head Neck. 2013;35(2):165-171.

19. Watanabe N, Noh JY, Narimatsu H, et al. Clinicopathological features of 171 cases of primary thyroid lymphoma: a long-term study involving 24,553 patients with Hashimoto's disease. Br J Haematol. 2011;153(2):236-243

20. Horning SJ, Weller E, Kim K, et al. Chemotherapy with or without radiotherapy in limited-stage diffuse aggressive non-Hodgkin's lymphoma: Eastern Cooperative Oncology Group study 1484. J Clin Oncol. 2004;22(15):3032-3038.

21. Miller TP, Dahlberg S, Cassady JR, et al. Chemotherapy alone compared with chemotherapy plus radiotherapy for localized intermediate- and high-grade non-Hodgkin's lymphoma. N Engl J Med. 1998; 339(1):21-26.

22. Beasley MJ. Lymphoma of the thyroid and head and neck. Clin Oncol. 2012;24(5):345-351.

23. Watanabe N, Narimatsu H, Noh JY, et al. Long-term outcomes of 107 cases of primary thyroid mucosa-associated lymphoid tissue lymphoma at a single medical institution in Japan. J Clin Endocrinol Metab. 2018;103(2):732-739.

24. Cha H, Kim JW, Suh CO, et al. Patterns of care and treatment outcomes for primary thyroid lymphoma: a single institution study. Radiat Oncol J. 2013;31(4):177-184.

25. Mian M, Gaidano G, Conconi A, et al. High response rate and improvement of long-term survival with combined treatment modalities in patients with poor-risk primary thyroid diffuse large B-cell lymphoma: an International Extranodal Lymphoma Study Group and Intergruppo Italiano Linfomi study. Leuk Lymphoma. 2011;52(5):823-832.

26. Doria R, Jekel JF, Cooper DL. Thyroid lymphoma. The case for combined modality therapy. Cancer. 1994;73(1):200-206.

27. Fuller LM, Krasin MJ, Velasquez WS, et al. Significance of tumor size and radiation dose to local control in stage I-III diffuse large cell lymphoma treated with CHOP-Bleo and radiation. Int J Radiat Oncol Biol Phys. 1995;31(1):3-11.

28. Laing RW, Hoskin P, Hudson BV, et al. The significance of MALT histology in thyroid lymphoma: a review of patients from the BNLI and Royal Marsden Hospital. Clin Oncol. 1994;6(5):300-304.

29. Sakorafas GH, Kokkoris P, Farley DR. Primary thyroid lymphoma (correction of lympoma): diagnostic and therapeutic dilemmas. Surg Oncol. 2010;19(4):e124-e129.

30. Belal AA, Allam A, Kandil A, et al. Primary thyroid lymphoma: a retrospective analysis of prognostic factors and treatment outcome for localized intermediate and high grade lymphoma. Am J Clin Oncol. 2001;24(3):299-305.
Cancer Management and Research

\section{Publish your work in this journal}

Cancer Management and Research is an international, peer-reviewed open access journal focusing on cancer research and the optimal use of preventative and integrated treatment interventions to achieve improved outcomes, enhanced survival and quality of life for the cancer patient. The manuscript management system is completely online and includes
Dovepress

a very quick and fair peer-review system, which is all easy to use. Visit http://www.dovepress.com/testimonials.php to read real quotes from published authors. 